\title{
Renal biopsy cases in myeloproliferative neoplasms (MPN)
}

\author{
Kumi Fujita $\cdot$ Kazuhiro Hatta
}

Received: 6 November 2012/ Accepted: 4 February 2013/Published online: 12 March 2013

(C) The Author(s) 2013. This article is published with open access at Springerlink.com

\begin{abstract}
We performed renal biopsy in three cases complicated by myeloproliferative neoplasms (MPN). Although several cases of glomerulonephritis associated with MPN have been reported, the etiologies of the renal disorders were not established (Plomley et al., Aust NZ J Med, 13:125-129, 1983; Sharma et al., Nephron, 69:361, 1995; Kanauchi et al., Intern Med, 33:36-40, 1994; Kasuno et al., Nephrol Dial Transplant, 12:212-215, 1997; Au et al., Am J Kid Dis, 34:889-893, 1999; Kosch et al., Nephrol Dial Transplant, 15:1710-1711, 2000; Oymak et al., Nephron, 86:346-347, 2000; Chun et al., Am J Nephrol, 20:344-346, 2000; Chung et al., Am J Nephrol, 22:397-401, 2002; Asaba et al., Clin Exp Nephrol, 7:296-300, 2003; Haraguchi et al., Clin Exp Nephrol, 10:74-77, 2006; Saigusa et al., J Nephrol, 19:656-658, 2006; Okuyama et al., Clin Nephrol, 6:412-415, 2007; Nishi et al., Clin Nephrol, 5:393-398, 2010; Ulusoy et al., Intern Med, 49:2477, 2010). A review of previous reports of renal biopsy cases with MPN in the English literature suggested that circulation control is important for the treatment of renal disorders that mimic glomerulonephritis in MPN.
\end{abstract}

Keywords Polycythemia vera - Essential thrombocytosis . Renal biopsy · Glomerulonephritis · Antihypertensive agent

K. Fujita $(\bowtie)$

Tenri Institute of Medical Research, 200 Mishima-cho,

Tenri, Nara, Japan

e-mail: fujiko@tenriyorozu.jp

K. Hatta

Tenri Hospital, Department of General Medicine,

200 Mishima-cho, Tenri, Nara, Japan

\section{Introduction}

Although several cases of glomerulonephritis with myeloproliferative neoplams (MPN) such as polycythemia vera (PV) or essential thrombocythemia (ET) have been reported, the association between MPN and glomerulonephritis is still obscure. The purpose of this article was to evaluate whether MPN can cause glomerulonephritis.

We describe three MPN cases in which renal biopsies were performed. Paraffin sections from the biopsied specimens of the three cases were examined with hematoxylin and eosin, periodic acid-Schiff, methenamine silver, and Masson's trichrome stains. Immunoglobulins ( $\operatorname{IgG}, \operatorname{IgA}$, and $\mathrm{IgM}$ ), complement (C3 and C1q), and fibrinogen were assessed by a direct immunofluorescence staining method on frozen sections for two cases and by immunostaining on paraffin sections for the other case. Electron microscopy was performed for all three cases.

Here, we also review previously reported cases in the English literature of renal glomerular disorders associated with MPN, which were examined by renal biopsy.

\section{Case reports}

Case 1

A 76-year-old woman with a history of bronchial asthma complained of edema. She had been diagnosed with thrombocytosis due to ET 3 years earlier. Her condition was stable at diagnosis, but edema occurred 2 months later, upon which administration of hydroxyurea was initiated.

The patient's height, weight, and blood pressure were $150 \mathrm{~cm}, 50 \mathrm{~kg}$, and $180 / 80 \mathrm{mmHg}$, respectively. She was alert and appeared healthy. She did not have any 
Fig. 1 Case 1. a Micrograph of the glomeruli showing mesangial proliferation and crescent formations.

b Immunoglobulin A deposition in the mesangial region of a glomerulus identified by immunostaining. c Electrondense deposits in the mesangial region
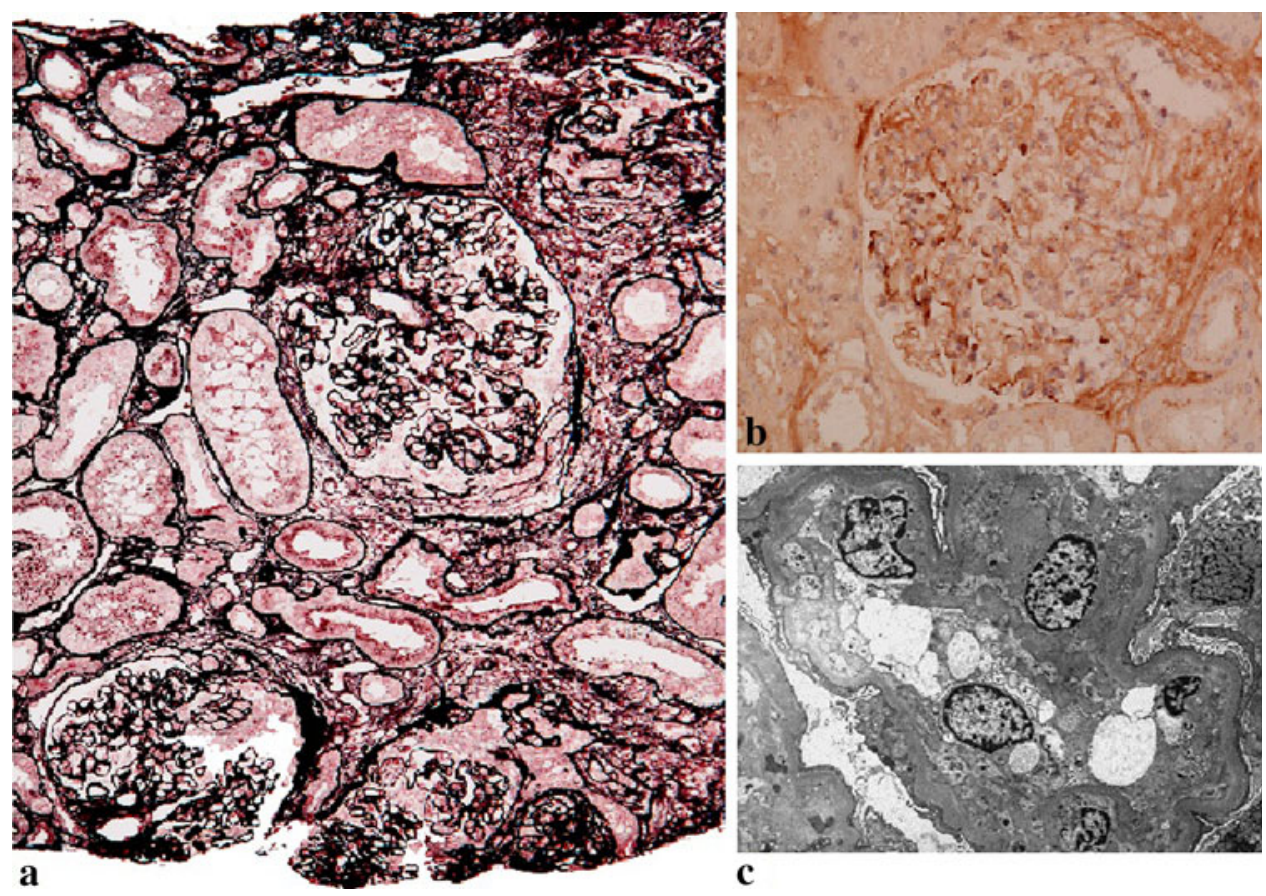

remarkable heart, lung, or abdominal abnormalities. Pitting edema was demonstrated in her lower extremity.

The laboratory data were as follows: hemoglobin, $15.8 \mathrm{~g} / \mathrm{dl}$; hematocrit, $47.3 \%$; platelets, $490,000 / \mu \mathrm{l}$; white blood cells, $8,100 / \mu \mathrm{l}, \mathrm{C}$-reactive protein, $<0.2 \mathrm{mg} / \mathrm{dl}$; blood urea nitrogen, $25.7 \mathrm{mg} / \mathrm{dl}$; serum creatinine, $1.2 \mathrm{mg} / \mathrm{dl}$; total cholesterol, $182 \mathrm{mg} / \mathrm{dl}$; total protein, $5.9 \mathrm{~g} / \mathrm{dl}$; albumin, $3.1 \mathrm{~g} / \mathrm{dl}$; globulin, $2.8 \mathrm{~g} / \mathrm{dl}$; lactate dehydrogenase, $241 \mathrm{IU} / \mathrm{l}$; aspartate aminotransferase, $18 \mathrm{IU} / \mathrm{l}$; alanine aminotransferase, $12 \mathrm{IU} / \mathrm{l}$; total bilirubin, $0.3 \mathrm{mg} / \mathrm{dl}$; $\gamma$-glutamyl transpeptidase, $25 \mathrm{IU} / \mathrm{l}$; alkaline phosphatase, $284 \mathrm{IU} / \mathrm{l} ; \mathrm{Na}, \quad 141 \mathrm{mmol} / \mathrm{l} ; \mathrm{K}, 4.8 \mathrm{mmol} / \mathrm{l} ;$ and $\mathrm{Cl}$, $109 \mathrm{mmol} / \mathrm{l}$. Urinalysis showed $3+$ proteinuria and $2+$ hematuria.

Renal biopsy was performed (Fig. 1); 13 glomeruli could be evaluated, 2 of which exhibited global sclerosis. Moderate mesangial proliferation with several crescents and arteriolosclerotic changes were observed. Immunohistological staining was positive for $\mathrm{IgG}$ and $\mathrm{IgA}$ with a granular pattern and negative for IgM, C1q, C3, and fibrinogen. Electron microscopy showed electron-dense deposits in the mesangium. The patient was diagnosed with IgA nephropathy with an active lesion, and treatment consisting of $30 \mathrm{mg}$ prednisolone, $50 \mathrm{mg}$ cyclophosphamide, and $80 \mathrm{mg}$ telmisartan per day was started. Although treatment improved the proteinuria and hematuria, the patient's serum creatinine level remained unchanged. Telmisartan decreased her blood pressure, but her hematocrit level could not be normalized. The patient experienced a complicated acute myocardial infarction 3 years later. She died 5 years later from ischemic bowel disorder and heart failure.
Case 2

A 62-year-old woman was admitted to our hospital because of general fatigue and chest discomfort. She had experienced acute glomerulonephritis 6 years previously, but the details of the clinical course were not known. Proteinuria had been detected while she was pregnant, and she had been treated for hypertension for 15 years. She had been diagnosed with ET at another hospital 3 years earlier. No remarkable cardiac problems were found when she was examined at the Department of Cardiology after admission. She was referred to the Department of General Medicine for a renal biopsy to investigate the persistent proteinuria.

The patient's height, weight, and blood pressure were $148 \mathrm{~cm}, 55 \mathrm{~kg}$, and $179 / 107 \mathrm{mmHg}$, respectively. Her consciousness level was alert and she looked well. A systolic murmur was detected at the 4 left sternal border. She did not have remarkable abnormalities in the lungs and abdomen and did not show pitting edema.

The laboratory data were as follows: hemoglobin, $11.4 \mathrm{~g} / \mathrm{dl}$; hematocrit, $39.8 \%$; platelets, $978,000 / \mu \mathrm{l}$; white blood cells, 14,400/ $\mu \mathrm{l}$; C-reactive protein, $<0.2 \mathrm{mg} / \mathrm{dl}$; blood urea nitrogen, $15.8 \mathrm{mg} / \mathrm{dl}$; serum creatinine, $0.7 \mathrm{mg} /$ $\mathrm{dl}$; total cholesterol, $227 \mathrm{mg} / \mathrm{dl}$; total protein, $7.3 \mathrm{~g} / \mathrm{dl}$; albumin, $4.5 \mathrm{~g} / \mathrm{dl}$; globulin, $2.8 \mathrm{~g} / \mathrm{dl}$; lactate dehydrogenase, $811 \mathrm{IU} / \mathrm{l}$; aspartate aminotransferase, $22 \mathrm{IU} / \mathrm{l}$; alanine aminotransferase, $11 \mathrm{IU} / \mathrm{l}$; total bilirubin, $0.3 \mathrm{mg} / \mathrm{dl}$; $\gamma$-glutamyl transpeptidase, $21 \mathrm{IU} / \mathrm{l}$; alkaline phosphatase, $470 \mathrm{IU} / \mathrm{l} ; \mathrm{Na}, 144 \mathrm{mmol} / \mathrm{l} ; \mathrm{K}, \quad 5.0 \mathrm{mmol} / \mathrm{l} ;$ and $\mathrm{Cl}$, $107 \mathrm{mmol} / \mathrm{l}$. Urinalysis showed $4+$ proteinuria (1.51 g/day) and no evidence of hematuria. 
Fig. 2 Case 2. a Micrograph of the glomeruli showing mesangial proliferation. b Interlobular artery with intimal thickening. c Immunoglobulin M deposition in the mesangial region of a glomerulus identified by immunostaining

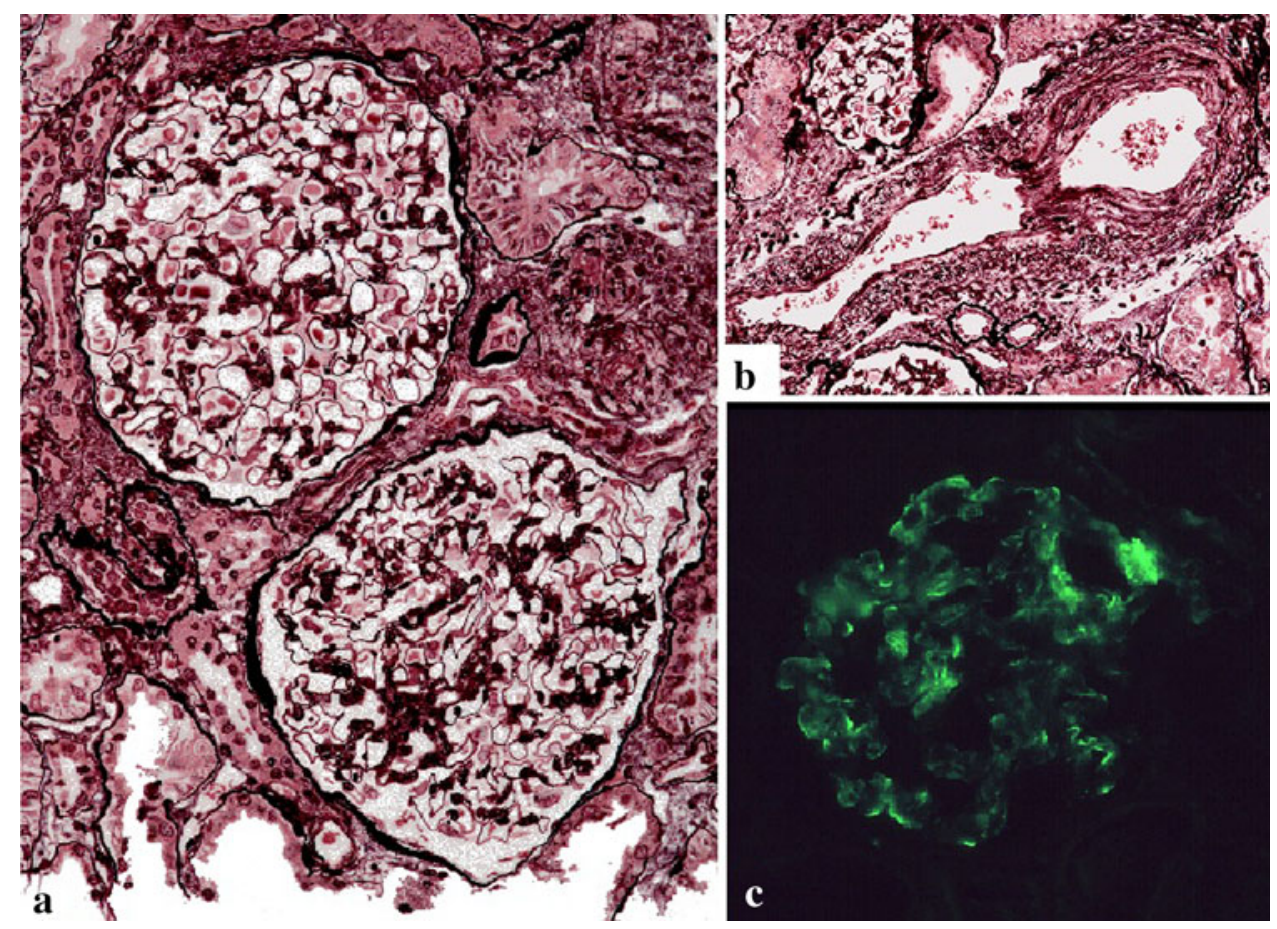

Renal biopsy was performed (Fig. 2), and 19 glomeruli could be evaluated, 2 of which exhibited global sclerosis. The histological findings included mild glomerular changes with arteriolosclerotic changes. Immunofluorescence staining was positive for IgM and weakly positive for IgA. Electron microscopy did not show any obvious electrondense deposits. She was treated with felodipine, an antihypertensive, as well as antiplatelet drugs. The control of her blood pressure was slightly poor. Her renal function remained stable, but the proteinuria persisted.

\section{Case 3}

A 51-year-old man was admitted to our hospital for renal biopsy. Proteinuria had been detected when the patient was approximately 30 years of age, and he had experienced tonsillitis several times. The patient had been diagnosed with PV with an abnormality of the JAK2 gene 3 years earlier. Renal biopsy was planned because his proteinuria had become more apparent over the past 2 years.

The patient's height, weight, and blood pressure were $165 \mathrm{~cm}, 66 \mathrm{~kg}$, and 120/73 mmHg, respectively. His consciousness level was alert, and he appeared healthy. No remarkable abnormalities were found in the heart, lungs, or abdomen, and pitting edema was not observed.

The laboratory data were as follows: hemoglobin, $15.3 \mathrm{~g} / \mathrm{dl}$; hematocrit, $48.1 \%$; platelets, $326,000 / \mu \mathrm{l}$; white blood cells, $8,400 / \mu \mathrm{l}$; C-reactive protein, $<0.2 \mathrm{mg} / \mathrm{dl}$; blood urea nitrogen, $22.2 \mathrm{mg} / \mathrm{dl}$; serum creatinine, $1.4 \mathrm{mg} / \mathrm{dl}$; total cholesterol, $194 \mathrm{mg} / \mathrm{dl}$; total protein, $7.1 \mathrm{~g} / \mathrm{dl}$; albu$\min , 4.1 \mathrm{~g} / \mathrm{dl}$; globulin, $3.0 \mathrm{~g} / \mathrm{dl}$; lactate dehydrogenase,
$169 \mathrm{IU} / \mathrm{l}$; aspartate aminotransferase, $17 \mathrm{IU} / \mathrm{l}$; alanine aminotransferase, $23 \mathrm{IU} / \mathrm{l}$; total bilirubin, $0.5 \mathrm{mg} / \mathrm{dl}$; $\gamma$-glutamyl transpeptidase, $21 \mathrm{IU} / \mathrm{l}$; alkaline phosphatase, $276 \mathrm{IU} / \mathrm{l} ; \mathrm{Na}, 139 \mathrm{mmol} / \mathrm{l} ; \mathrm{K}, 4.7 \mathrm{mmol} / \mathrm{l} ;$ and $\mathrm{Cl}$, $106 \mathrm{mmol} / \mathrm{l}$. Urinalysis showed $4+$ proteinuria $(1.2 \mathrm{~g} /$ day $)$ and no evidence of hematuria.

Renal biopsy was performed (Fig. 3) and 22 glomeruli could be evaluated, 5 of which showed global sclerosis. Histological findings included mesangial proliferative glomerulonephritis with crescents and focal segmental necrosis. Arteriosclerotic changes were also observed. Immunofluorescence staining was positive and revealed strong immunoreactivity for $\operatorname{Ig} \mathrm{A}$ and $\mathrm{C} 3$. Electron microscopy showed electron-dense deposits in the mesangium. He was diagnosed with IgA nephropathy. Tonsillectomy plus steroid pulse therapy and an angiotensin II receptor blocker were selected as treatments for the patient. His proteinuria and hematuria disappeared after 6 months.

\section{Discussion}

According to the World Health Organization classification, MPNs are classified into the following six diseases: PV, ET, chronic myelogenous leukemia (CML), primary myelofibrosis (PMF), chronic neutrophilic leukemia (CNL), and chronic eosinophilic leukemia/hypereosinophilic syndrome (CEL/HES) [16]. Most reports of glomerular disease associated with MPN have involved PV or ET, whereas few reports have described associations with PMF, CML, $\mathrm{CNL}$, or CEL/HES. We limited our subjects to cases with 
Fig. 3 Case 3. a Micrograph of the glomeruli showing mesangial proliferation. b Micrograph of the glomeruli showing a fibrocellular crescent formation. c Immunoglobulin A deposition in the mesangial region of a glomerulus identified by immunostaining. d Electron-dense deposits in the paramesangial region

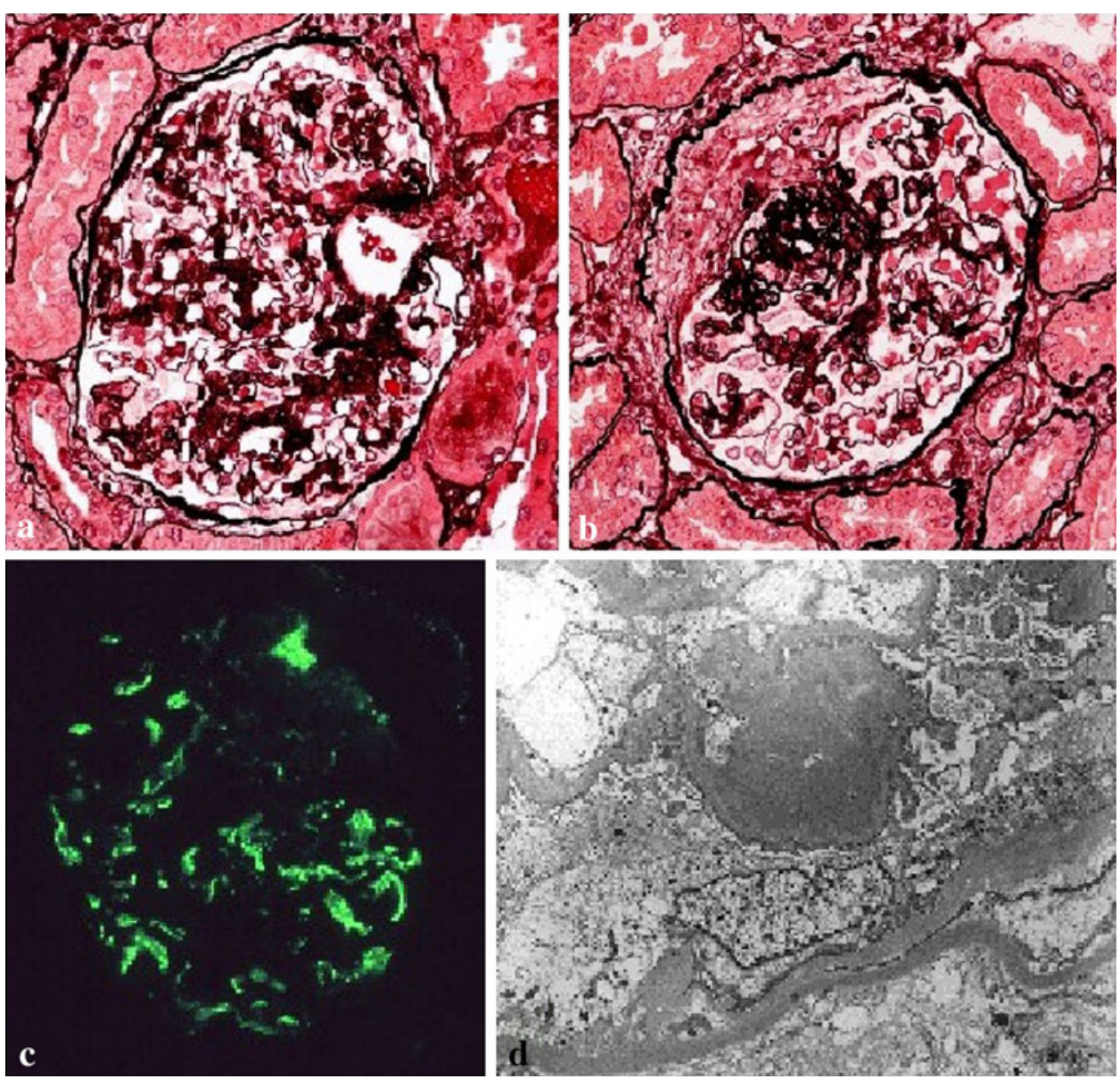

PV or ET in this study and found 21 appropriate cases in the English literature between 1980 and 2010 [1-15].

The 21 cases in the literature and our 3 cases are shown in Table 1 [1-15].

The average patient age of these 24 cases (16 men and 8 women) was 55.1 years. PV was found in 17 patients and ET in 7 patients. Of the 24 cases, 5 cases, including 2 of ours, were diagnosed with $\operatorname{IgA}$ nephropathy (IgAN) after renal biopsy: focal segmental glomerulosclerosis (FSGS) in 10 cases, membranous glomerulonephritis in 1 case, membranoproliferative glomerulonephritis in 1 case, purpura nephritis in 1 case, and fibrillary glomerulonephritis in 1 case. The other 5 cases were not specified. Hypertension was observed in 20 of 24 cases. Treatments consisted of antihypertensive drugs for 13 patients, phlebotomy for 12 patients, corticosteroid for 8 patients, hydroxycarbamide for 8 patients, and cyclophosphamide for 4 patients. Urinalysis improvement was seen in 13 cases, 9 of which were treated with antihypertensive agents, 7 with phlebotomy, and 6 with corticosteroid. Four cases worsened despite treatment.

Cases of glomerular disease associated with MPN have been reported occasionally. Although Au et al. [5] detected 5 cases of FSGS (3.6\%) among 138 patients with MPN, the frequency of glomerular disorders among MPN patients is unknown. Therefore, reports that various types of glomerular disease are associated with MPN indicate that the pathogenesis of this condition is complex. Au et al. suggested that high platelet counts and abnormal activation of megakaryocytes are predisposing factors for glomerulosclerosis and that aggressive treatment to lower the platelet count can prevent the development of renal abnormalities [5]. On the other hand, antihypertensive agents, such as an angiotensin II receptor blocker (ARB), were selected for treatment because of complication of hypertension. Ulusoy reported the successful treatment of 1 case with antihypertensive drug administration and phlebotomy [15]. A good response after phlebotomy was observed in 2 cases $[3,6]$. MPN, especially PV and ET, are susceptible to complication by thrombosis or hypertension [17]. Alternation of renal hemodynamics in patients with MPN might cause glomerular endothelial injury. Endothelial cell damage could induce activation of platelets and release of cytokines such as PDGF (platelet-derived growth factor). Floege et al. [18] suggested that PDGF might mediate glomerular injury and cause exacerbation of glomerulonephritis. They clarified that PDGF could induce mesangial and endothelial cell proliferation. Other candidate 


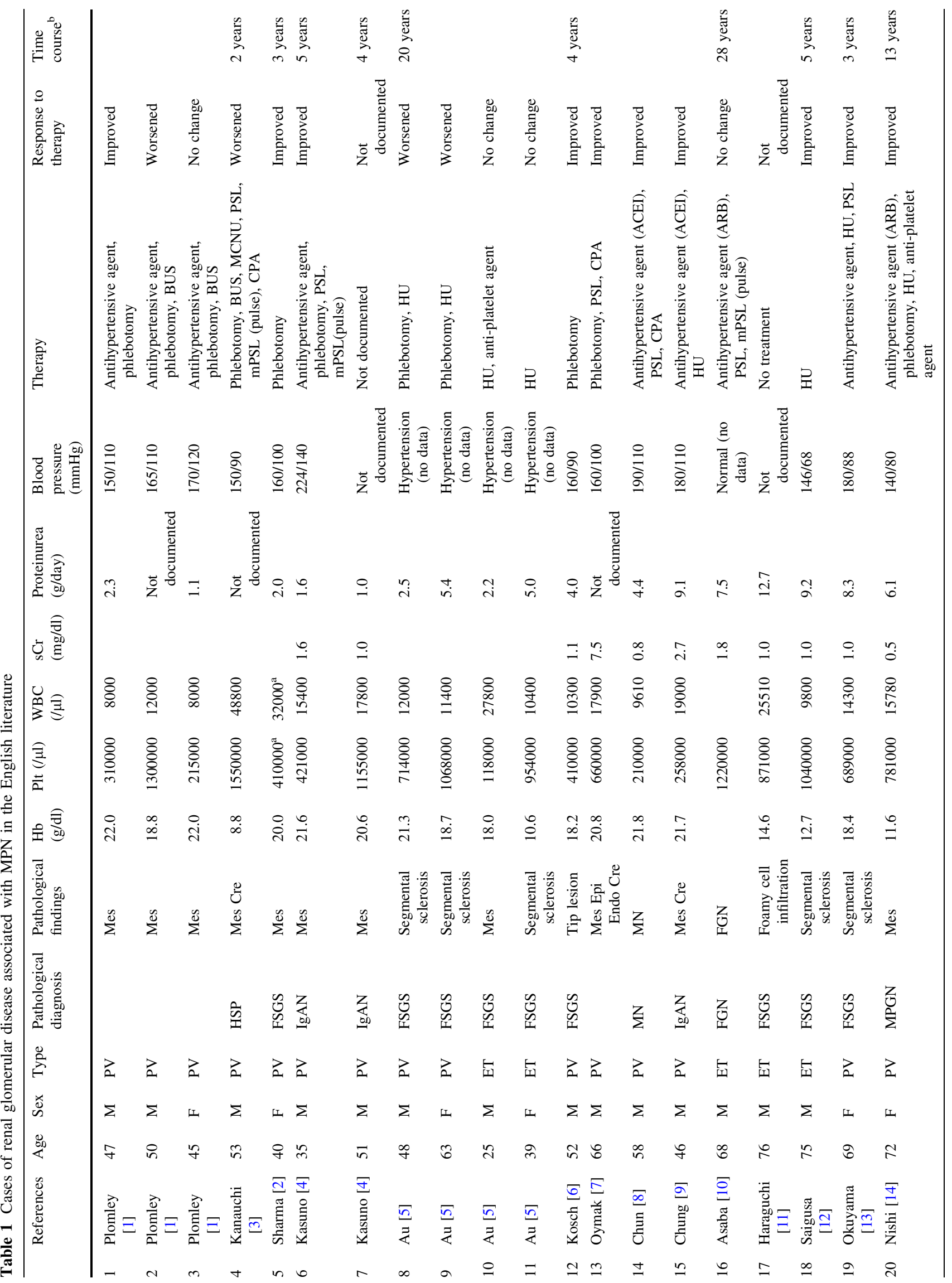




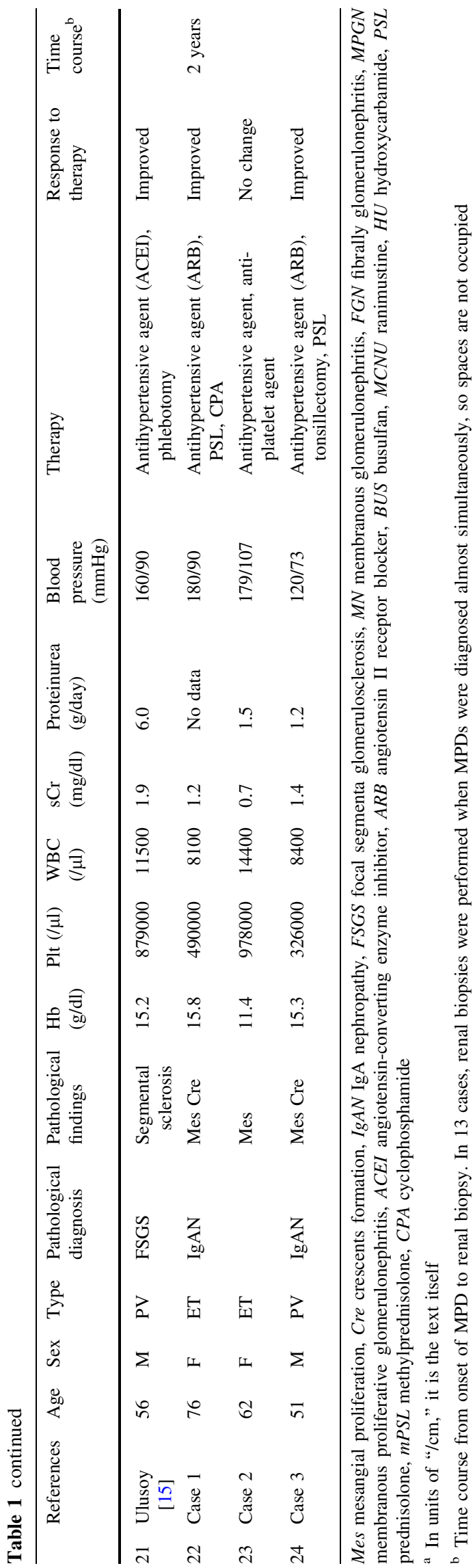

cytokines such as insulin-like growth factor-1, plateletactivating factor, transforming growth factor- $\beta$, and plasmalemmal vesicle-associated protein- 1 had been reported to play a role in the pathogenesis of glomerulonephritis in MPN patients, though a definite role for these factors has not been established [2, 4, 5, 14]. Sharma et al. [2] and Kosch et al. [6] reported that improvement of hematocrit levels might be useful for reducing protein urea and recovering renal function. Controlling renal hemodynamics and blood cell proliferation might be important for improving renal disease in MPN patients. Unfortunately, with regard to our cases, the effectiveness of these treatments could not be clarified.

Regarding the clinical course, glomerulonephritis was thought to have preceded MPN in 2 of our cases (cases 2 and 3). In case 1, a case of IgA nephropathy, the onset of IgA nephropathy did not occur until 2 years after the PV diagnosis. Although the documented onset of MPN preceded renal disease in 9 of the 21 previously reported cases, a period of 10 years or more passed between the onset of MPN and that of renal disease in 3 cases, indicating that an association between MPN and the onset of renal disease is unlikely. In those cases, glomerular diseases were considered to simply overlap with MPN. However, MPN might exacerbate glomerular disease because of the alternation of renal hemodynamics at least in part.

Conflict of interest The authors report no financial or other conflict of interest relevant to the subject of this article.

Open Access This article is distributed under the terms of the Creative Commons Attribution License which permits any use, distribution, and reproduction in any medium, provided the original author(s) and the source are credited.

\section{References}

1. Plomley RF, Kincaid-Smith PS, Sullivan JR, Fairley KF, Whitworth JA, Brown RW. Polycythemia vera and glomerulonephritis. Aust NZ J Med. 1983;13:125-9.

2. Sharma RK, et al. Focal segmental glomerulosclerosis in a patient with polycythemia rubra vera. Nephron. 1995;69:361.

3. Kanauchi M, Dohi K, Shiiki H, Fujii Y, Ishikawa H. HenochShönlein purpura nephritis associated with polycythemia vera. Intern Med. 1994;33:36-40.

4. Kasuno K, et al. IgA nephropathy associated with polycythemia vera: accelerated course. Nephrol Dial Transplant. 1997;12: $212-5$.

5. Au WY, Chan KW, Lui SL, Lam CCK, Kwong YL. Focal segmental glomerulosclerosis and mesangial sclerosis associated with myeloproliferative neoplasms. Am J Kid Dis. 1999;34: 889-93.

6. Kosch M, et al. Focal sclerosis with tip lesions secondary to polycythaemia vera. Nephrol Dial Transplant. 2000;15:1710-1.

7. Oymak $\mathrm{O}$, et al. Polycythemia vera presenting with rapidly progressive glomerulonephritis and pyoderma gangrenosum. Nephron. 2000;86:346-7. 
8. Chun SL, et al. Secondary polycythemia associated with idiopathic membranous nephropathy. Am J Nephrol. 2000;20:344-6.

9. Chung J, Park PG, Song K. IgA nephropathy in a patient with polycythemia vera. Am J Nephrol. 2002;22:397-401.

10. Asaba K, et al. Fibrillary glomerulonephritis associated with essential thrombocytosis. Clin Exp Nephrol. 2003;7:296-300.

11. Haraguchi $\mathrm{K}$, et al. Focal segmental glomerulosclerosis associated with essential thrombocythemia. Clin Exp Nephrol. 2006;10:74-7.

12. Saigusa $\mathrm{T}$, et al. A case of essential thrombocytosis developing nephrotic syndrome and severe endothelial damage. J Nephrol. 2006;19:656-8.

13. Okuyama $\mathrm{S}$, et al. Focal segmental glomerulosclerosis associated with polycythemia vera: report of a case and review of the literature. Clin Nephrol. 2007;6:412-5.
14. Nishi Y, et al. Histopathological manifestations of membranoproliferative glomerulonephritis and glomerular expression of plasmalemmal vesicle-associated protein- 1 in a patient with polycythemia vera. Clin Nephrol. 2010;5:393-8.

15. Ulusoy $\mathrm{S}$, et al. Absence of hypoalbuminemia despite nephrotic proteinuria in focal segmental glomerulosclerosis secondary to polycythemia vera. Intern Med. 2010;49:2477.

16. Swerdlow S, Campo E, Lee Harris N, Jaffe E, Pileri S, Stein H, et al. WHO classification of tumors of hematopoietic and lymphoid tissues, 4th ed. Lyon: IARC Press; 2008.

17. Landolfi R, Di Gennaro L. Thrombosis in myeloproliferative and myelodysplastic syndrome. Hematology. 2012;17:S174-6.

18. Floege J, et al. Glomerular cell proliferation and PDGF expression precede glomerulosclerosis in the remnant kidney model. Kidney Int. 1992;41:297. 